\title{
The impact of intensive care admission criteria on elderly mortality
}

\author{
Marco Túlio Gualberto Cintra ${ }^{1}$ \\ (iD) Dinah Belém² \\ (iD) Edgar Nunes Moraes ${ }^{3}$ \\ (iD) Fernando Antônio Botoni ${ }^{4}$ \\ Maria Aparecida Camargos Bicalho ${ }^{5}$
}

\begin{abstract}
1. Geriatra. Professor Adjunto do Departamento de Clínica Médica da UFMG, Belo Horizonte, MG, Brasil 2. Geriatra. Colaborador do Ambulatório de Geriatria do Hospital das Clínicas da UFMG, Belo Horizonte, MG, Brasil 3. Geriatra. Professor Associado do Departamento de Clínica Médica da UFMG, Belo Horizonte, MG, Brasil 4. Intensivista. Professor Adjunto do Departamento de Clínica Médica da UFMG, Belo Horizonte, MG, Brasil
\end{abstract} 5. Intensivista e Geriatra. Professor Associado do Departamento de Clínica Médica da UFMG, Belo Horizonte, MG, Brasil

\section{SUMMARY}

OBJECTIVE: To review systematically the influence of admission criteria on the mortality of elderly patients under intensive therapy. METHODS: We performed a search on the PUBMED and BIREME databases by using the MeSH and DeCS terms "intensive care units", "patient admission", and "aged" in Portuguese, English, and Spanish. Only prospective and retrospective cohort studies were included. We analyzed the severity score, type of hospital admission, quality of life, co-morbidities, functionality, and elderly institutionalization.

RESULTS: Of the 1,276 articles found, thirteen were selected after evaluation of the inclusion and exclusion criteria. It was observed that the severity score, functionality, and co-morbidities had an impact on mortality. It was not possible to determine which severity score was more suitable.

CONCLUSION: We suggest that analysis of functionality, co-morbidities, and severity scores should be conducted to estimate the elderly mortality in relation to the admission to intensive care units.

KEYWORDS: Patient selection. Aged. Critical care. Hospital mortality. Intensive care units.

\section{INTRODUCTION}

Population aging represents a challenge to healthcare systems worldwide, particularly regarding issues related to healthcare financing and professional qualification. The care for elderly patients differs from that for adult patients at all levels of medical assistance, including intensive care'.

In 2010, the number of individuals aged 65 years or older reached 524 million people, approximately $8 \%$ of the world's population. By 2050 , it is estimated that the elderly population will reach 2 billion people, that is, $22 \%$ of the world's population. In the period from 2010 to 2050, the population growth rate will be $22 \%$ for the age group between 0 and 64 years, whereas for the elderly population that rate will be $188 \%$, reaching up to $351 \%$ in the population older than 85 years $^{2,3}$.

In Brasil, the demographic transition is occurring rapidly. While in France it took 150 years for the per- 
centage of the elderly population to double from 10\% to $20 \%$, in Brasil this phenomenon will happen only within two decades ${ }^{3}$. In 2014, people older than 60 years reached $13.7 \%$ of the population of Brasil ${ }^{3}$. The age group above 80 years old is the one that increases most in the country as its growth rate has been above $4 \%$ a year for the past two decades ${ }^{4}$.

The mean age of the patients admitted for intensive care is also a reflection of population aging. A study of 35 intensive care units (ICUs) in the region of Paris, France, demonstrated an increase in the mean age from 52.1 to 57.1 years old between 1993 and 2004. In the past decade, the mean age of the intensive care patients increased at a rate of 6 months a year, whereas in the general population that rate was lower, only 3 months a year ${ }^{5}$. Recent studies have indicated that half of ICU admissions are of patients older than 65 years, with 10\% older than 80 years, and 5-6\% older than 85 years ${ }^{5,6}$.

This rapid demographic transition without the due preparation of intensive care units has stimulated changes in their profile, which in turn explains the admission of elderly patients with no well-defined literature-based criteria, including the use of empirical procedures and application of protocols derived from studies, which excludes the majority of the elderly people'.

Therefore, the objective of this study was to review systematically the influence of admission criteria on the mortality among elderly patients under intensive therapy.

\section{METHODS}

In 2015, the authors conducted a search for articles published on the PUBMED and BIREME databases using the MeSH terms "intensive care units", AND "patient admission" AND "aged" as well as DeCS terms "terapia intensive” AND "idoso" AND “admissão de paciente". Articles written in English, Portuguese and Spanish were searched. All the studies found in the literature had their abstracts read critically, and their references were used to search for other works, which had not been selected from the above-cited databases.

Only prospective and retrospective cohort studies using criteria for admission to intensive care units were selected; those including patients younger than 18 years old in their samples were excluded. Nevertheless, articles comparing elderly patients to subjects younger than 60 years old were evaluated. In addition, studies specifically addressing age as a unique variable for risk factor of mortality in ICU patients or assessing outcomes exclusively related to a disease or specifically related to a type of surgery were also excluded. Studies using no multivariate analysis of the results were not included either. All the studies meeting the inclusion criteria were fully read.

For evaluation of the criteria for patient admission to intensive care units, the following items were analyzed: quality of life, co-morbidities, severity scores measured at ICU admission, type of admission (surgical versus clinical and elective versus urgent/emergency patients), and comparison between institutionalized (those attending long-term care institutions for the elderly) versus non-institutionalized patients. In all articles published, the impact of the variables on mortality was investigated on a long-term and intra-hospital basis.

\section{RESULTS}

As observed in Figure 1, a total of 1,361 articles published in the MEDLINE and BIREME databases were selected by using the above-cited descriptors. Eighty-five publications were found to be repeated, thus totaling 1,276 studies whose abstracts were critically read. Of these, only those with prospective or retrospective cohort design and presenting a theme related to the admission criteria for intensive care were selected for review, resulting in 34 publications for full reading. In the end, thirteen studies met all the inclusion criteria described above.

All the selected studies assessed the impact of severity scores, which had been measured at admission, on the mortality in intensive care units on a long-term and intra-hospital basis. The same could not be described regarding the other variables evaluated, particularly quality of life and care for institutionalized patients, which were addressed by only one article each (Table 1). Methodological aspects of the selected publications were also listed in Table 1. A summary of the results found will be described below according to the variables analyzed.

\section{INSTITUTIONALIZATION}

Only the study by Bagshaw et al. ${ }^{12}$ evaluated the impact of patient admission to ICUs based on individuals attending long-term care institutions 
TABLE 1. METHODOLOGY AND VARIABLES RELATED TO ADMISSION OF ELDERLY PATIENTS TO INTENSIVE CARE IN THE STUDIES SELECTED

\begin{tabular}{|c|c|c|c|c|c|c|c|c|}
\hline & $\begin{array}{l}\text { Sample } \\
\text { number of } \\
\text { patients }\end{array}$ & Methodology & $\begin{array}{l}\text { Instituti- } \\
\text { olisation }\end{array}$ & $\begin{array}{l}\text { Type } \\
\text { of admis- } \\
\text { sion }\end{array}$ & $\begin{array}{l}\text { Func- } \\
\text { tionality }\end{array}$ & $\begin{array}{l}\text { Severity } \\
\text { Score }\end{array}$ & $\begin{array}{l}\text { Comor- } \\
\text { bidities }\end{array}$ & $\begin{array}{l}\text { Quality } \\
\text { of life }\end{array}$ \\
\hline Lown DJ et al. ${ }^{7}$ (2013) & 506 & Retrospective Cohort & & & & $x$ & $x$ & \\
\hline Fuchs L et al. ${ }^{\mathbf{8}}$ (2012) & 7265 & Prospective Cohort & & $x$ & & $x$ & $x$ & \\
\hline Nasa P et al. ${ }^{\mathbf{9}}$ (2012) & 132 & Prospective Cohort & & & & $x$ & & \\
\hline Roch A et al. ${ }^{10}(2011)$ & 299 & Prospective Cohort & & & $x$ & $x$ & $x$ & \\
\hline $\begin{array}{l}\text { Burkmar JA \& Iyengar R }{ }^{11} \\
\text { (2011) }\end{array}$ & 599 & Prospective Cohort & & & & $x$ & & \\
\hline Bagshaw SM et al. ${ }^{12}$ (2009) & 15640 & Retrospective Cohort & $x$ & $x$ & & $x$ & $x$ & \\
\hline Sacanella E et al. ${ }^{13}$ (2009) & 230 & Prospective Cohort & & & $x$ & $x$ & $x$ & $x$ \\
\hline Nannings B et al. ${ }^{\mathbf{1 4}}$ (2008) & 12993 & Retrospective Cohort & & & & $x$ & & \\
\hline Ryan D et al. ${ }^{15}(2008)$ & 245 & Retrospective Cohort & & $x$ & & $x$ & & \\
\hline $\begin{array}{l}\text { Brunner-Ziegler S et al. }{ }^{16} \\
(2007)\end{array}$ & 3069 & Prospective Cohort & & & & $x$ & & \\
\hline Vosylius S et al. ${ }^{6}$ (2005) & 2067 & Prospective Cohort & & $x$ & & $x$ & $x$ & \\
\hline Boumendil A et al. ${ }^{17}$ (2004) & 233 & Prospective Cohort & & & $x$ & $x$ & $x$ & \\
\hline Mahul P et al. ${ }^{18}(1991)$ & 295 & Prospective Cohort & & $x$ & $x$ & $x$ & & \\
\hline
\end{tabular}

FIGURE 1. ORGANOGRAM FOR PUBLICATION SELECTION.

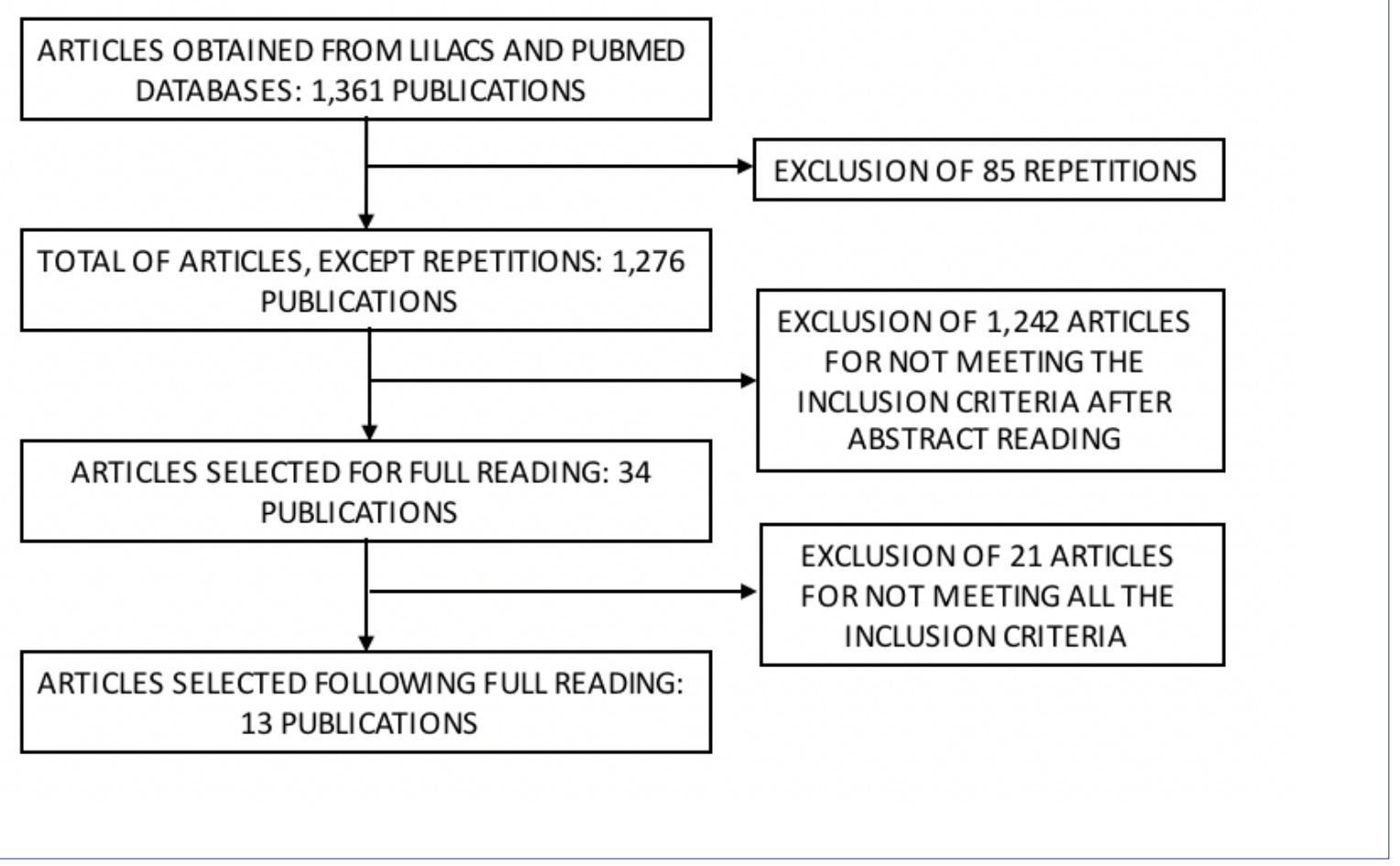

for the elderly. Of the 120,123 patients evaluated, $1.3 \%$ was from these institutions. Being an institutionalized individual was associated with higher intra-hospital mortality (OR 1.35; 95\%CI 1.09-1.67; $\mathrm{p}=0.005)$ and lower survival time after discharge $(\mathrm{p}<0.001)^{12}$.

\section{TYPE OF ADMISSION}

This variable was evaluated in five publications, among which three found no association between type of admission (surgical versus clinical and elective versus urgent/emergency patients) and mortality, namely, Fuchs et al. ${ }^{8}$, Vosylius et al. ${ }^{6}$, and Mahul et al. ${ }^{18}$. 
Bagshaw et al. ${ }^{12}$, however, reported that individuals older than 80 years admitted to ICUs on an emergency basis due to surgical reasons or who need hospitalization for non-surgical conditions show higher intra-hospital mortality $(\mathrm{p}<0.001)$. Similar results were described by Ryan et al. ${ }^{15}$, who related them to mortality among patients older than 65 years during the intensive care unit stay $(\mathrm{p}<0.001)$.

\section{FUNCTIONALITY}

The functionality at the ICU admission was addressed by four studies, which used the Karnofsky index, Knaus classification, pre-admission health status (PHS), and Barthel and Lawton-Brody scales. Of these publications, only that by Roch et al. ${ }^{10}$, who used multivariate analysis, found no association between functionality at ICU admission and high mortality.

Mahul et al. ${ }^{18}$ reported an association between functional decline at admission and higher mortality within 1 year after ICU discharge $(p<0.001)$. According to Sacanella et al. ${ }^{13}$, the Lawton-Brody scale is associated with higher cumulative mortality (intra-hospital mortality added to that after hospital discharge) in the multivariate analysis $(p=0.047)$. Boumendil et al. ${ }^{17}$ reported an association between decline in daily-life activities (DLAs) and higher mortality after ICU discharge $(p<0.010)$, with a decrease in survival time among elderly patients from 851 to 106 days.

\section{SEVERITY SCORE}

All the articles selected assessed severity scores in elderly patients at ICU admission. In two of these studies, Burkmar \& Iyengar ${ }^{11}$ and Nannings et al. ${ }^{14}$, the effectiveness of severity scores was assessed, whereas the other works addressed the association between results obtained and mortality.

The following scales were used by the studies reviewed: Simplified Acute Physiology Score I (SAPS I) ${ }^{8,18}$, Simplified Acute Physiology Score II (SAPS II) $)^{6,10,14,16,17}$, Acute Physiology and Chronic Health Disease Classification System II (APACHE II) 7,9,11-13,15, Acute Physiology and Chronic Health Disease Classification System III (APACHE III) ${ }^{7,12}$, Acute Physiology and Chronic Health Disease Classification System IV (APACHE IV) ${ }^{11}$, OMEGA Score System ${ }^{13}$, Palliative Performance Index (PPI) ${ }^{11}$, Sequential Organ Failure Assessment (SOFA) ${ }^{6,8,13}$, and Patient Rule Induction Method (PRIM) ${ }^{14}$.
Of the twelve studies assessing the above-cited scales in relation to mortality, seven showed an association with hospital and/or long-term mortality ${ }^{6,8,10,12,15,16,18}$. Only three studies reported no such association ${ }^{7,9,17}$. On the other hand, Sacanella et al. ${ }^{13}$ demonstrated an association with higher hospital mortality and no association with cumulative mortality (intra-hospital mortality added to that after hospital discharge).

Burkmar \& Iyengar ${ }^{11}$ compared the effectiveness of APACHE IV to that of PPI in relation to the mortality. The authors reported higher sensitivity and higher negative predictive value for APACHE IV compared to PPI and when compared to the association of APACHE IV with PPI. Nannings et al. ${ }^{14}$ used PRIM to screen subgroups of patients older than 80 years at high risk of ICU mortality, reporting effectiveness similar to that of SPAS II, although fewer data were needed and the groups were more homogeneous.

\section{CO-MORBIDITIES}

The co-morbidities were addressed by seven articles selected. The studies used the McCabe, Charlson, and Elixhauser scales to quantify the number of co-morbidities or assess them individually in the statistical analyses. Of these studies, two found no association between co-morbidities and higher mortality among elderly patients in ICUs, namely, Sacanella et al. ${ }^{13}$ using the Charlson scale and Vosylius et al. ${ }^{6}$ evaluating cardiac, respiratory, renal, and hepatic diseases in conjunction. Fuchs et al. ${ }^{8}$ used the Elixhauser scale and reported that co-morbidities at ICU admission were associated with higher mortality within 28 days ( $p$ $<0.001)$ and 1 year $(\mathrm{p}<0.001)$. Roch et al. ${ }^{10}$ and Boumendil et al. ${ }^{17}$, who used the McCabe scale, reported higher long-term mortality when the patient had a potentially fatal co-morbidity, with $p$ values of 0.018 and 0.0001 , respectively. Roch et al. ${ }^{10}$ also evaluated the hospital mortality and reported a p-value $<0.001$.

Lown et al. ${ }^{7}$ studied the impact of several co-morbidities on mortality and reported that the diagnosis of coronary arterial disease changed the ICU mortality at the statistical threshold $(p=0.055)$, but without altering the long-term mortality. Bagshaw et al. ${ }^{12}$ reported that the presence of two or more co-morbidities was associated with higher hospital mortality in individuals older than 80 years $(p=0.001)$. 


\section{QUALITY OF LIFE}

A study by Sacanella et al. ${ }^{13}$ assessed the influence of quality of life on the ICU mortality in elderly patients by using the EuroQoL-5D instrument. In multivariate analysis, the quality of life decreased at admission was found to be independently associated with higher cumulative mortality at $\mathrm{p}=0.005^{13}$.

\section{DISCUSSION}

The majority of the variables studied to define ICU admission criteria for elderly patients have not been extensively investigated in the literature. One can highlight that the influence of both quality of life and admission of institutionalized elderly patients were explored only in a single article despite the significant association with higher ICU mortality ${ }^{12,13}$. However, it is early to draw any conclusion on these topics.

The majority of articles on type of admission, namely, surgical versus clinical and elective versus urgent/emergency patients, show conflicting results and therefore, we do not recommend this type of evaluation for estimation of mortality prior to admission of elderly patients until new studies determine the effectiveness this type of analysis ${ }^{6,8,2,15,18}$.

Functionality represents a very interesting alternative for screening ICU patients with better prognosis. The majority of the authors reported that functional decrease was significantly associated with mortality $^{13,17,18}$. It is suggested that functionality should be evaluated by analyzing DLAs before admission to ICU.

Another relevant issue is that an association of the number of co-morbidities and their severity with mortality was observed in the majority of the studies reviewed. Therefore, it is recommended that an analysis of the co-morbidities in elderly patients should be performed as a criterion for ICU admission ${ }^{7,8,10,12,17}$.

All the articles selected evaluated severity scores in elderly patients at ICU admission. The majority of the studies demonstrated an association of this variable with mortality, thus indicating that this score is useful for screening elderly patients for intensive care $^{6,10,12,13,15,16,18}$. Despite the existence of several valid scales, there are few studies comparing these instruments to each other, and consequently, it is impossible to determine which is the most suitable severity score for the elderly ${ }^{11,14}$. SOFA is currently the most widely used and recommended instrument for assessing the severity of organ dysfunction in patients with infection, with the cut-off point of two above the patient's baseline score ${ }^{19}$.

The present study has limitations. One of them is related to the restriction to three languages and to two databases (i.e. PUBMED and BIREME) for selection of the scientific articles, which might have reduced the number of relevant publications. Another limitation is that the variables studied were specifically assessed in relation to the mortality without analyzing the quality of life and functionality after hospital discharge, which might also have contributed to the exclusion of relevant publications.

\section{CONCLUSION}

We have concluded that the analysis of functionality and co-morbidities should be part of the evaluation of elderly patients before admission to intensive care in order to screen those individuals who can benefit from this type of assistance. The clinical severity scores should be part of this analysis. However, it is not possible to state which is the best instrument to use for the elderly. In fact, there is a lack of studies determining whether analysis of quality of life, type of admission, and patient institutionalization should be routinely performed as a criterion for ICU admission.

Conflict(s) of interest: none

\section{RESUMO}

OBJETIVO: Revisar sistematicamente a influência dos critérios de admissão na mortalidade em pacientes idosos em terapia intensiva. MÉTODOs: Realizamos uma busca nas bases de dados PubMed e Bireme, utilizando os termos MeSH e DeCS "intensive care units", "patient admission" e "aged" em português, inglês e espanhol. Somente estudos de coorte prospectivos e retrospectivos foram incluídos. Foram analisados o escore de gravidade, tipo de internação hospitalar, qualidade de vida, comorbidades, funcionalidade e institucionalização do idoso.

RESULTADOS: Dos 1.276 artigos encontrados, 13 foram selecionados após avaliação de seus critérios de inclusão e exclusão. Observou-se que o escore de gravidade, a funcionalidade e as comorbidades tiveram impacto na mortalidade. Não foi possível determinar qual escore de gravidade foi mais adequado.

CONCLUSÃO: Sugerimos que a análise da funcionalidade, de comorbidades e de escores de gravidade seja realizada para estimar a mortalidade dos idosos em relação à internação em unidades de terapia intensiva.

PALAVRAS-ChaVE: Seleção de pacientes. Idoso. Cuidados críticos. Mortalidade hospitalar. Unidades de terapia intensiva. 


\section{REFERENCES}

1. Cintra MTG, Belém D, Bicalho MA. O idoso na terapia intensiva. PROAMI 2011;8(2):25-117.

2. National Institute on Aging. Global health and aging. [cited 2015 Feb 14] Available from http://www.nia.nih.gov/sites/default/files/global_health_ and_aging.pdf.

3. Neumann LTV, Albert SM. Aging in Brazil. The Gerontologist. 2018;58(4):611-17.

4. Brito F. A transição demográfica no Brasil: as possibilidades e os desafios para a economia e sociedade. Belo Horizonte: Cedeplar, Universidade Federal de Minas Gerais; 2007.

5. Boumendil A, Somme D, Garrouste-Orgeas M, Guidet B. Should elderly patients be admitted to the intensive care unit? Intensive Care Med. 2007;33(7):1252.

6. Vosylius S, Sipylaite J, Ivaskevicius J. Determinants of outcome in elderly patients admitted to the intensive care unit. Age Ageing. 2005;34(2):15762.

7. Lown DJ, Knott J, Rechnitzer T, Maclsaac C. Predicting short-term and long-term mortality in elderly emergency patients admitted for intensive care. Crit Care Resusc. 2013;15(1):49-55.

8. Fuchs L, Chronaki CE, Park S, Novack V, Baumfeld Y, Scott D, et al. ICU admission characteristics and mortality rates among elderly and very elderly patients. Intensive Care Med. 2012;38(10):1654-61.

9. Nasa $P$, Juneja $D$, Singh $O$, Dang R, Arora V. Severe sepsis and its impact on outcome in elderly and very elderly patients admitted in intensive care unit. J Intensive Care Med. 2012;27(3):179-83.

10. Roch A, Wiramus S, Pauly V, Forel JM, Guervilly C, Gainnier M, et al. Longterm outcome in medical patients aged 80 or over following admission to an intensive care unit. Crit Care. 2011;15(1):R36.
11. Burkmar JA, lyengar R. Utility of the APACHE IV, PPI, and combined APACHE IV with PPI for predicting overall and disease-specific ICU and ACU mortality. Am J Hosp Palliat Care. 2011;28(5):321-7.

12. Bagshaw SM, Webb SA, Delaney A, George C, Pilcher D, Hart GK, et al. Very old patients admitted to intensive care in Australia and New Zealand: a multi-centre cohort analysis. Crit Care. 2009;13(2):R45.

13. Sacanella E, Pérez-Castejón JM, Nicolás JM, Masanés F, Navarro M, Castro $P$, et al. Mortality in healthy elderly patients after ICU admission. Intensive Care Med. 2009;35(3):550-5.

14. Nannings B, Abu-Hanna A, de Jonge E. Applying PRIM (Patient Rule Induction Method) and logistic regression for selecting high-risk subgroups in very elderly ICU patients. Int | Med Inform. 2008;77(4):272-

15. Ryan D, Conlon N, Phelan D, Marsh B. The very elderly in intensive care: admission characteristics and mortality. Crit Care Resusc. 2008;10(2):10610.

16. Brunner-Ziegler S, Heinze G, Ryffel M, Kompatscher M, Slany J, Valentin A. "Oldest old" patients in intensive care: prognosis and therapeutic activity. Wien Klin Wochenschr. 2007;119(1-2):14-9.

17. Boumendil A, Maury E, Reinhard I, Luquel L, Offenstadt G, Guidet B. Prognosis of patients aged 80 years and over admitted in medical intensive care unit. Intensive Care Med. 2004;30(4):647-54.

18. Mahul P, Perrot D, Tempelhoff G, Gaussorgues P, Jospe R, Ducreux JC, et al. Short- and long-term prognosis, functional outcome following ICU for elderly. Intensive Care Med. 1991;17(1):7-10.

19. Singer M, Deutschman CS, Seymour CW, Shankar-Hari M, Annane, D, Bauer M, et al. The Third International Consensus Definitions for Sepsis and Septic Shock (Sepsis-3). JAMA. 2016:315(8):801-10. 